\title{
A River Runs Through It: Territory of Opportunistic Coexistence
}

\author{
ADRIANA CUELLAR \\ University of San Diego \\ MARCEL SANCHEZ PRIETO \\ Woodbury University
}

In order to understand urban development in Latin America we must study the actions of an opportunistic environment that enables social progress. Usually urban adaptations react to the pressures of a contested territory, that if seen as survival tactics, they amplify urban regeneration, where illicit acts of urbanism become primary sites of innovation.

Such is the example of the international border between San Diego, and Tijuana. This region is no exception of witnessing the territorial conflicts and crime scenes that are typical characteristics of border regions. In particular this border encounters the highest massive migration from Latin America to the US and back (deportees), making the dividing line - in this case the Tijuana river canal - a site of urban dialectics.

The channelized river has tangibly revealed the mutations and interactions of opposing realities that expose overtones, exigencies, neglected issues and/or cutting edge cultural movements. It is at this hotbed and funneling point of two countries where illicit acts of urbanism are accepted. Emblematic of an opportunistic landscape, opposing modes of operations are in some cases ignored for the sake of coexistence.

\section{LEGAL OPPORTUNISM: CONTESTED LAND}

While rivers have traditionally been magnets for urban development and crucial resources for city growth, the Tijuana River Watershed before becoming a canal has been one of power struggles; its unique condition of being divided by a polemic line, makes it a site of extreme vulnerability to the imbalanced economic and political forces in which it exists.
Early traces of urban framework in Tijuana started in 1889 as an urban grid designed by the Mexican engineer Ricardo Orozco. The grid gave birth to a small border town located near the natural course of the river that remained unarticulated and shared by the two countries. It was indeed the result of a land dispute between two families(1). The establishment of this grid would have never imagined the deep acceleration of urban growth that the city will experience in the following century.

One of the first opportunities setting a standard for urban permissiveness happened during the Prohibition in the United States from 1919 to 1933 . The US investment flowed across the nearest border from Los Angeles and Hollywood, transforming Tijuana into the most convenient locus for illicit entertainment and vice, an early model for Las Vegas' development in the late forties. Tijuana enjoyed an economic and urban boom and a society of tolerance emerged, giving credence to the idea that Tijuana was a lawless place for gambling, drinking, prostitution and the selling of restricted goods, where impunity had settled and to which the added processes of urban growth went unchecked and without governance. Tijuana evolved as the opportunistic legal alternative to the over-regulated illegal activities of its northern neighbor(2). This ambiance of permissiveness penetrated into the physical urban form of the city and set violations to the Orozco's urban plan, diagonal streets where blurred in favor to increase the density of buildings for entertainment. Simultaneously, the Tijuana River Watershed remained untouched in the midst of a rapidly growing urban center.

The enormous economic boom influenced politicians and foreign investors to develop the most important casino in the region: the Casino Agua Caliente, an ambitious project that changed the typology of casinos into glamorous resorts, shows, race tracks and thermal baths; an important destination for actors, gangsters and politicians; it remained a destination after the prohibition, until Mexican president Lazaro Cardenas prohibited casinos in the nation.

These events frame the first 40 years of the city, its urban grid reached its full capacity and expanded beyond its center. The pattern 


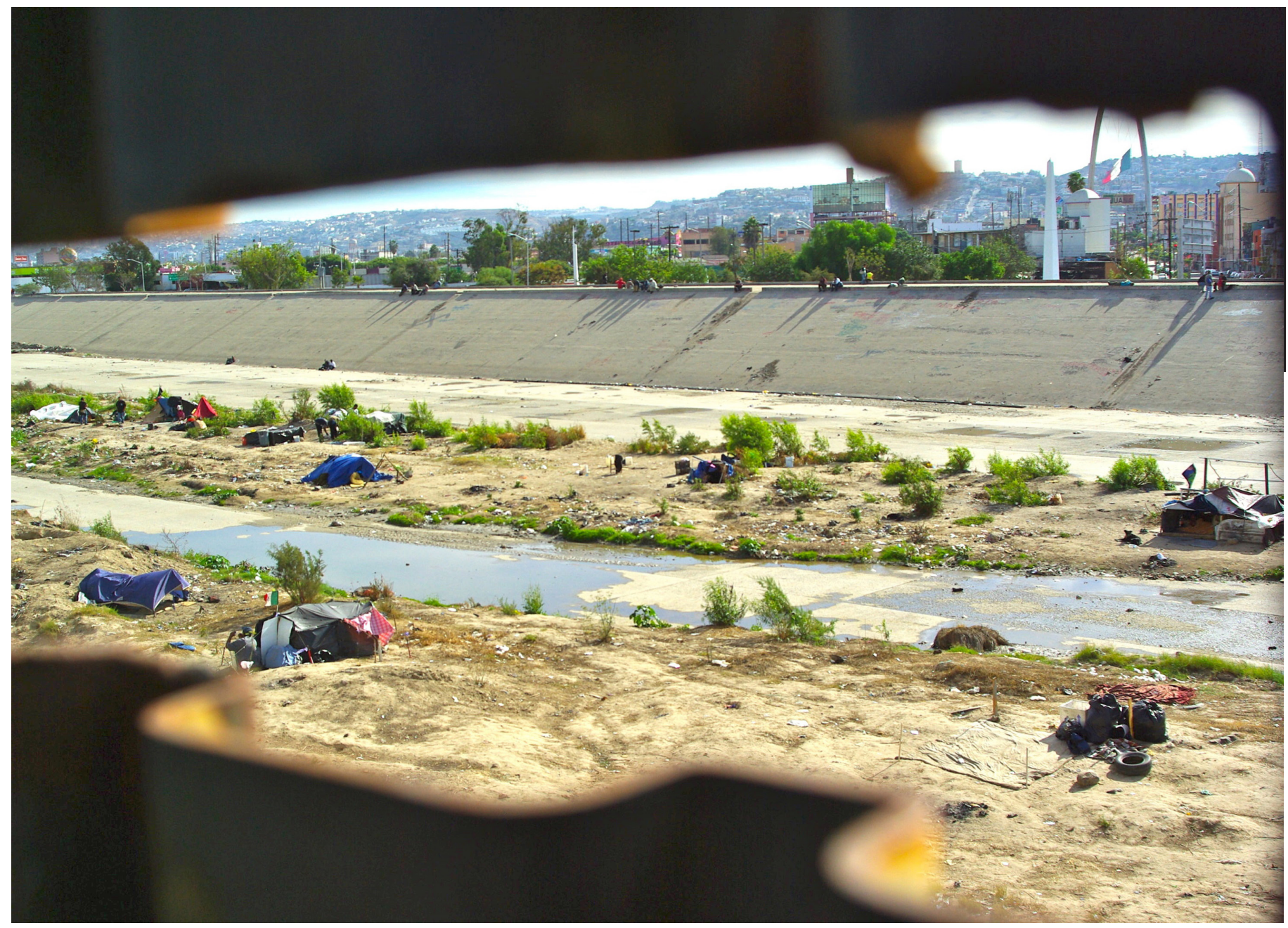

Figure 1: View of ñongos (C) Wildcoast (Flickr)

for habitation along the river started to drastically change in the late nineteen forties with the construction of the bridge, Puente México, that spanned over the river and connected the border crossing with the city center. Construction workers and their families built a large irregular settlement near the job site inside the unregulated riverbank. Government quickly took strong action, displacing the illegal 300 homes to new colonias in the southeast periphery of the city. To further prevent the growth of illegal settlements, public recreational projects were built on sites that were likely to attract this type of development. Nonetheless, illegal construction persisted. More than 1,500 people illegally appropriated the watershed through the 1950's and the government continued to look for new areas to displace them. By 1955 all homes at the river watershed had been entirely removed(3).

Opportunistic actions are often understood as advantageous conditions, selfish appropriations of surrounding circumstances, where the primary intention is to gain something. However, opportunism is not able to exist without risk taking. After the displacements of 1955, Tijuana continued to receive massive number of migrants from various parts of México in search for jobs in both Tijuana and the United States. The population reached nearly 60,000 inhabitants, four times the population of the previous decade. Scarcity of housing in Tijuana forced migrants to appropriate once again the vacant river watershed.

Seizing the opportunity to build on unclaimed but illegal land, an alternative community called Cartolandia - denoting the dystopia of Disneyland - emerged where families of workers in transition settled using recycled materials such as cardboard and corrugated sheet metal. Inhabitants of Cartolandia accepted the dangers of living in flash flood riverbanks with precarious structures for the sake of proximity and location to economic resources. The need for land triggered a survivalist mentality among migrants, superseding rational city planning.

\section{THE OPPORTUNISTIC DISGUISE OF MODERNISM}

As illegal invasions continued to occupy the riverbank, local government concerns escalated to a national level. Under the auspices of modernization, the canalization of the Tijuana River became the most ambitious national urban development of the time. Construction commenced in 1972 for a 100-year floodplain scenario, a tactic of minimum risk, setting a clean slate for maximum control. Over 1500 cartolandia families were once again evicted. Tijuana turned from 


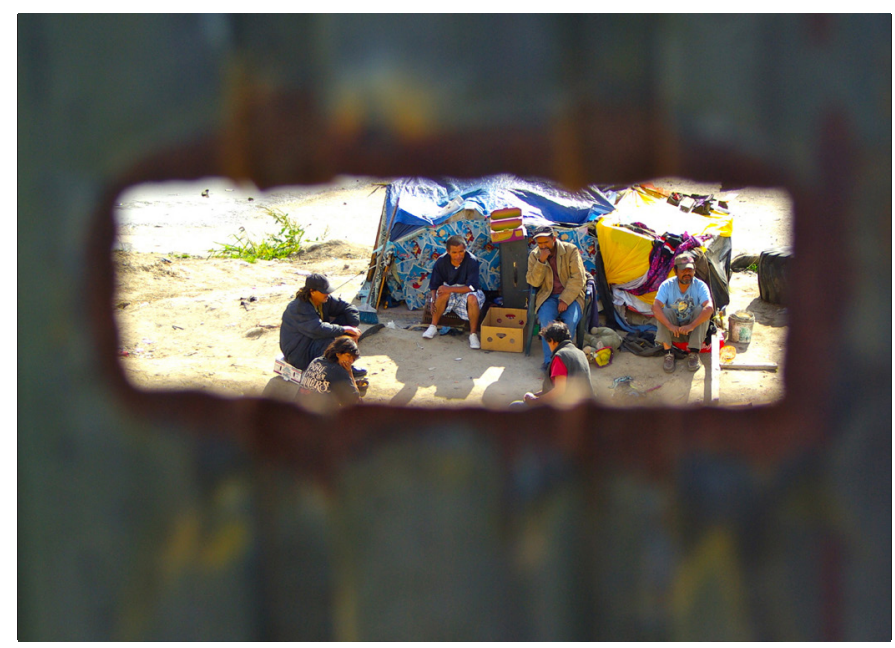

Figure 2: View of ñongos (C) Wildcoast (Flickr)

being a border town into a modern city; the project involved large parcel lots and grand buildings for public administration, culture, commerce, and housing. However, the vision of Tijuana's bright economic future mirrored by urban planning has continued to be challenged by the realities of this contested territory.

The development around Zona Rio or river zone has created the financial center of the city, however shady legal practices still persist. While gambling, bars and prostitution fulfilled the illegal desires of US citizens in the past, Zona Rio now provides cheap and legal pharmaceuticals, medical practices and hospital facilities to its northern neighbor's over controlled health system. The massive canal infrastructure at the core of the city is an ongoing space that acts as an urban zone that allows speculation and appropriation, legal and illegal. It's presence has defined the city permanently, a weak social bandage to the underlying problems that caused illegal settlements, intensifying its need for urban reinvention.

\section{OPPORTUNISM OF TOLERANCE: COEXISTENCE BETWEEN LEGALITY AND ILLEGALITY}

With the recent economic crisis in the United States, immigrants have again become a major target. United States' politicians and government officials have refocused their attention on this social group extraditing a record number of undocumented citizens from the U.S. The overwhelming deportations to Tijuana reached record numbers in the last decade(4). Even in Tijuana, a city accustomed to accelerated population growth(5), this influx of transient people has put the city into a state of emergency.

Recently, these circumstances frame, once again, the Tijuana River Canal as a site for opportunism. New settlements called ñongos have started popping up in the recent years since the U.S. economic crisis. The ñongos are makeshift bunkers built inside the concrete bed of the canal. They are built using recycled materials, however, they differ from the Cartolandia of the 1970's because these settlements are underground and made up entirely of deportees(6). The image of hope and sanitized tactics of modernization from the 70's crumbles at the fringe of the canal. The ñongos disappear from civilians as a shameful reflection of the city unwilling to accept them. They embody the negligence of both nations. These people are abandoned and rejected by two hostile governments and mostly powerless to leave. Many of these people lack official documents, are unable to find work, and are perceived as criminals in both countries; they are confined to this stretch of infrastructure: a no man's land as the only alternative to settle.

However, the ñongos have become the crucible for the development of an opportunistic community that lives outside the law. Illegal activity is rampant: born of the legal blind spots of a conflicting and fragmented territory where uncertainty is omnipotent and the ephemeral and volatile is recognized as a dialectic asset of regularized society. Although the community is riddled with obstacles - security, crime and drugs - this fringe is strategic and sought out, it provides a release from the overburdened population, a means to address problems outside the law in a city unable or indifferent to deal with the needs of a marginalized population.

Regardless of ongoing efforts by the authorities to sanitize the canal, displaced deportees (either in prison, shelters and streets) continue to aim to cross the border. The canal becomes a monument of hope, a horizon that escapes from the involuntary illegal and inhumane condition. Deportees, similar to the Roman term "homo sacer", are men in bare foot deprived of any rights yet resist rejection and continue to seek integration.

Social progress is not only revealed in architecture, urban modernization, expression of the arts, or in something as intangible as national policy, but in how we turn informal population and places into assets of internal cultural values that evoke local and regional collectiveness. The history of the river suggests that Tijuana is in constant erasure and resistance to its deep social and urban problems. The Tijuana canal continues to urge academics, students and professionals to speculate on real and imaginative scenarios of what the border canal could become. The fragile and monumental nature of the site continues to stimulate the imaginary of the city's potential and extraordinary opportunistic nature.

The repeated marginalization of the Tijuana River Watershed is a reminder that infrastructures of extreme control can be missed opportunities for urban integration and renewal. One example is the thesis project by the student Joseph Ruiz Tapia suggests a Piranesian reading of the canal, where ruins are catalyst for public appropriations and hybrid urban inventions, a gorilla approach towards a populist opportunism. Another example is the proposal by architect Alberto Kalach, taking advantage of the city's inability to maintain the canal, the project may be read as a decay and oversight of the channel as means to reclaim its natural state, an environmental opportunism. A real project under construction is the Zócalo 11 de Julio, a massive civic space embracing the canal towards city hall, a governmental disguise to claim this territory for commercialization by private investors, a civic and territorial opportunism. 


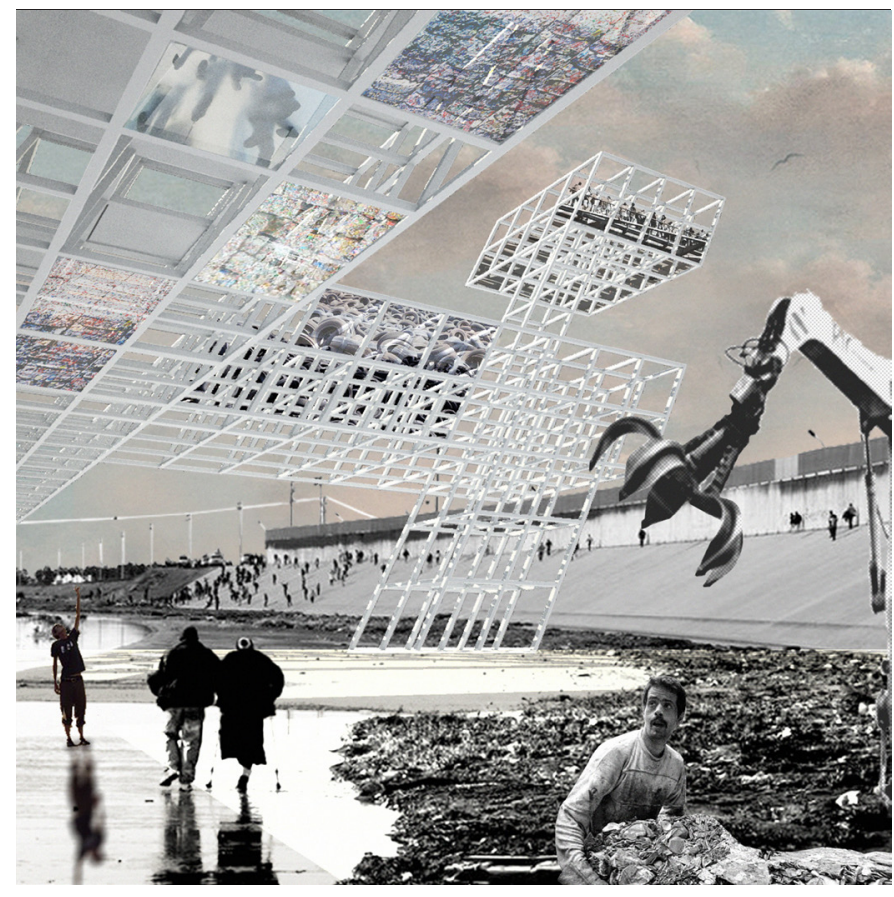

Figure 3: Opportunistic Landscape (C) CRO studio with Joseph Ignacio Ruiz Tapia. Ann Karen Higadera.

Deaf to the needs of the transient population and immutable to the forces of a dynamic yet extremely hierarchic society, the physical violations of the canal project renders new quests for legislations of civic coexistence. Our images present a speculative project about a border that imagines a structural mechanism that could become a medium to cope, coexist and take advantage of discrepancies associated with the territory, a space that dignifies and registers an ongoing mutable history, capable to unfold radical transformations at the limits of control.

It is not the intention to neither romanticize nor exemplify this settlement as a model for urban generation. As borders harden between nations with economic imbalances, Tijuana uncovers the nature of opportunism as a medium to contest legal actions and a mechanism to cope, coexist and challenge the established structures of two nations, an opportunistic landscape that holds promise for resisting the alienation associated with traditional urban models of control.

\section{ENDNOTES}

1. The railway system in California was introduced in 1869 , unifying northern California with the east of the US. In 1876 the railway reached Los Angeles, and in 1882 it arrived to San Diego. The railway together with the propaganda on California's dream land provoked a massive migration from east to west, reaching across to Ensenada in Baja California with the construction of a grand residential development for Americans in México. The Argüello and Olvera, different land owners of the Tijuana ranch, sought an opportunity in residential development and decided to partition their land. The judicial authority sanctioned their land dispute on July 11 th 1889 , giving rise to the first urban plan, the date is considered the official birth of Tijuana. (David Piñera and Jesús Ortiz in collaboration with Madgaleno Robles, Inicios de Tijuana como Asentamiento Urbano. Historia de Tijuana, Semblanza General, Universidad Autónoma de Baja California, XI Ayuntamiento de Tijuana, Centro de Investigaciones Históricas UNAM-UABC, 1985)

2. Tijuana grew from having 30 cantinas to 90 in the lapse of 4 years The New York Times 1929 \& History Channel.

3. Antonio Padilla Corona. Desarrollo Urbano, Capítulo XXII. Historia de Tijuana, Semblanza General, Universidad Autónoma de Baja California, XI Ayuntamiento de Tijuana, Centro de Investigaciones Históricas UNAM-UABC, 1985.

4. According to U.S. Immigration and Custom Enforcement (ICE) statistics, 360,172 Mexicans have been deported to Tijuana from 2003 to 2012. (http://www.ice.gov)

5. In Tijuana's short history of 125 years, the city has reached a population of nearly 2 million, its majority composed by immigrants. (Apuntes de Población de Baja California, Comité de Planeación para el Desarrollo del Estado, COPLADE. Gobierno del Estado, 2013)

6. Laura Velasco and Sandra Albicker. Assessment and characteristics of the population residents in "El Bordo" of the Tijuana River Canal. Executive Report of research results, El Colegio de la Frontera Norte, Tijuana October 2013.

\section{BIBLIOGRAPHY}

- David Piñera and Jesús Ortiz in collaboration with Madgaleno Robles, Inicios de Tijuana como Asentamiento Urbano. Historia de Tijuana, Semblanza General, Universidad Autónoma de Baja California, XI Ayuntamiento de Tijuana, Centro de Investigaciones Históricas UNAM-UABC, 1985

- Antonio Padilla Corona. Desarrollo Urbano, Capítulo XXII. Historia de Tijuana, Semblanza General, Universidad Autónoma de Baja California, XI Ayuntamiento de Tijuana, Centro de Investigaciones Históricas UNAM-UABC, 1985

- U.S. Immigration and Custom Enforcement (ICE) statistics. http://www.ice.gov

- Notes on Baja California's Population, Comité de Planeación para el Desarrollo del Estado, COPLADE. Gobierno del Estado, 2013

- Laura Velasco and Sandra Albicker. Assessment and characteristics of the population residents in "El Bordo" of the Tijuana River Canal. Executive Report of research results, El Colegio de la Frontera Norte, Tijuana October 2013

- Camillo Boano in conversation with Óscar Benassini. The coordinates of Risk, Urbanisms of Profanation. La Tempestad Magazine, México August 2013 


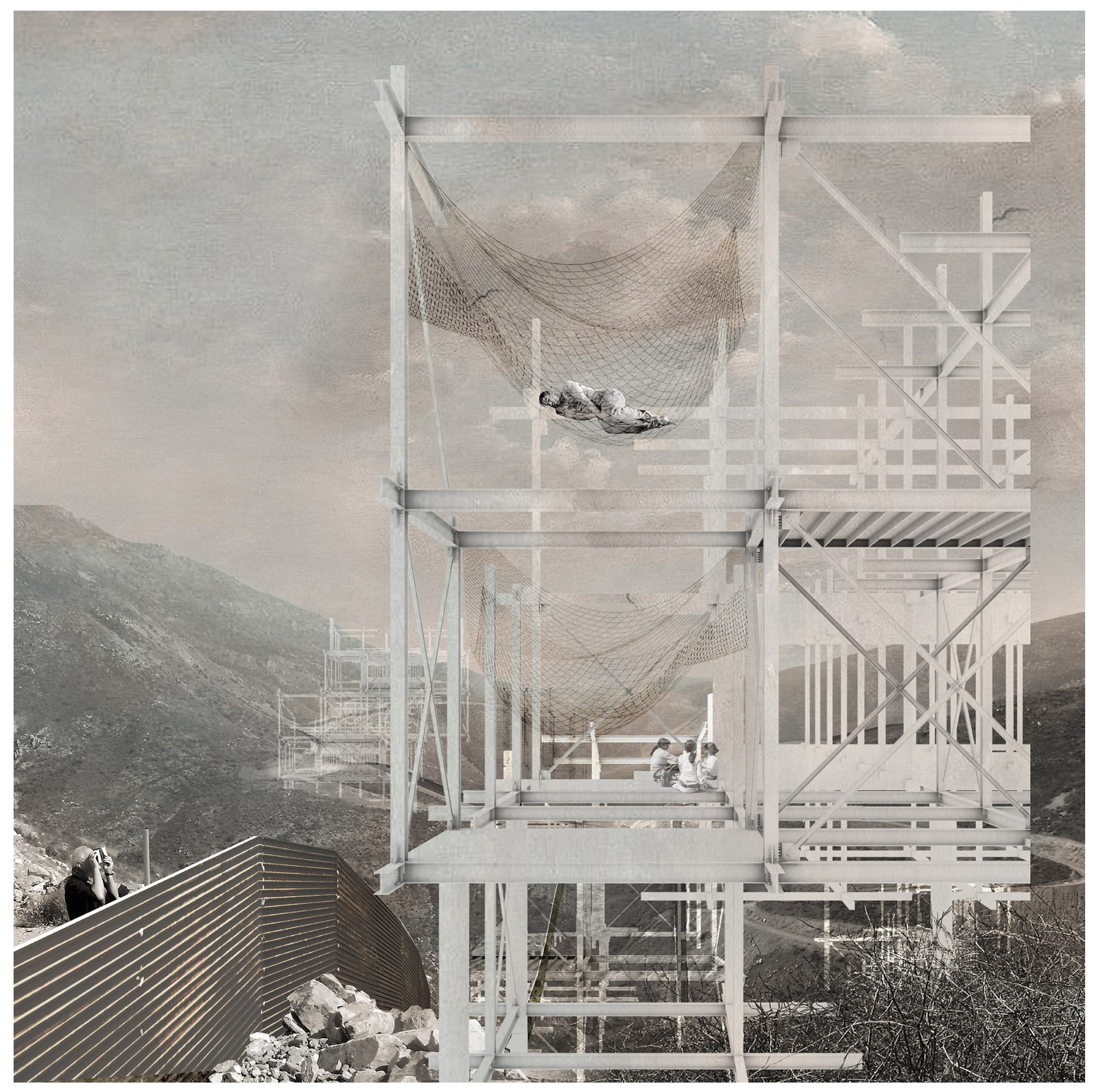

Opportunistic Landscape (C) CRO studio with Joseph Ignacio Ruiz Tapia. Ann Karen Higadera.. 